\title{
Magnitude of Family Planning Use in Gardi Village Development Committee of Chitwan district
}

\author{
${ }^{1}$ Dinesh Kumar Malla \\ ${ }^{1}$ Birendra Multiple Campus, Bharatpur, Chitwan, Nepal
}

\begin{abstract}
The estimated contraceptive prevalence rate of Chitwan is based on the data of health management and information system. Therefore, this study aimed to find out the actual magnitude of family planning use among different age groups, castes, educational status, etc. A cross-sectional descriptive study was conducted in Gardi village development committee of Chitwan district from June 15, 2012 to July 5, 2012. A total of 246 married women of reproductive age were studied, who were obtained from 410 households selected from the total households of the village development committee using stratified proportionate random sampling technique. Structured interview was done and data were analyzed using SPSS version 16. Percentages of the variables were calculated and cross-tabulations were done. The percentage of family planning use was $65 \%$, increasing after the age of thirty years- $70 \%$ on average in each age group thereafter. More Dalits (76\%) used family planning methods than Janajatis (58\%). About three quarters of women were met with primary education and $69 \%$ of illiterates used family planning, with the least percentage (37\%) among those with SLC and above education. Most common method was male sterilization (41\%), followed by female sterilization (21\%). The reasons for not using family planning were given as: no need of family planning (78\%), feared side-effects (17\%) and did not know any methods (5\%). For an awareness program of family planning, couples with caste Janajati, those having education SLC and above and younger age groups should be given more priority.
\end{abstract}

Key words: Family Planning, Magnitude, Chitwan

Corresponding address : Dinesh Kumar Malla, Birendra Multiple Campus, Bharatpur, Chitwan. E-mail: dineshmalla13@yahoo.com

\section{INTRODUCTION}

Some 215 million women who would prefer to delay or avoid pregnancy still lack access to safe and effective contraception. ${ }^{1}$ Family planning continues to be a priority for the government of Nepal and is highlighted in the current three year interim development plan (2010-2012). ${ }^{2}$ The targets of family planning programme of Nepal are: to increase the contraceptive prevalence rate (CPR) of all methods from 48 percent in 2006 to 67 percent by 2015 and to increase the CPR of Modern Contraceptive Methods from 44\% in 2006 to $55 \%$ in $2015 .{ }^{3}$ Still the CPR of Nepal is only $50 \%{ }^{4}$ and that of Chitwan is also the same. ${ }^{5}$ However, the CPR of Chitwan has been estimated on the basis of the data of health management and information system (HMIS) and it is not complete as some couples who take the service from other sources such as a medical shop rather than the health system may be missed in HMIS. Therefore, the primary objective of this study was to find out the magnitude of family planning use among different age groups, castes, educational status, etc.

\section{MATERIALS AND METHODS}

A cross-sectional descriptive study was conducted in Gardi village development committee (VDC) of Chitwan district from June 15, 2012 to July 5, 2012. An orientation was provided to the students of bachelor of public health who collected the data of the study. Pretesting was done by them in another VDC. A total of 410 households were estimated using formula $n=z^{2} p q / 1^{2}$, putting the prevalence $47 \%$ of fourth antenatal care visit and allowable error $11 \%$ and adding the non-respondent rate $10 \%$. The 410 households were selected using stratified proportionate random sampling technique out of total households of the VDC. Stratification was done on the basis of caste groups. In the total selected households, there were 246 eligible couples for family planning. Verbal consent was obtained from the respondent before starting the interview. Face-to-face structured interview was done with the married women of reproductive age. Data were entered and analyzed using statistical software program for social science (SPSS 16.0). Frequency and percentage distribution as well as cross-tabulation of variables was done.

\section{RESULTS}

\section{Socio-demographic situation}

Out of 246 study mothers, almost all, $98 \%$ were hindu, while regarding caste more than fifty percent (54\%) were Janjati followed by Brahman/Chhetri (32\%) and Dalit 14\%. With respect to economic status, an equal proportion, i.e., $40 \%$ of respondents had their major source of income sufficient for 6-12 months and more than one year and half of this had income sufficient for less than 6 months.

There were around $19 \%$ women on average in each age groups from 25 to 44 years, whereas the women in the age groups $15-19,20-24$, and $45-49$ were $4 \%, 11 \%$, and $8 \%$ respectively. About 3 in 4 women were housewives and almost a quarter were involved in agriculture, while $58 \%$ of husbands worked in agriculture, the proportion of husbands in labour and foreign employment was almost equal. Regarding educational status, 
Malla DK. Magnitude of Family Planning Use in...... JHAS, 2013, Vol. 3, No. 1 P 40-43

$14 \%$ and $12 \%$ of husbands were illiterate and had informal education respectively, while these proportions for women were higher, i.e., $22 \%$ and $27 \%$. However, the proportions in primary, secondary and SLC and above were higher among males than that among females.

Table 1: Socio-demographic characteristics of women

\begin{tabular}{|c|c|c|}
\hline Socio-demographic characteristics & $\begin{array}{c}\text { Frequency } \\
(\mathrm{N}=\mathbf{2 4 6})\end{array}$ & Percent \\
\hline \multicolumn{3}{|l|}{ Caste } \\
\hline Brahman/Chhetri & 78 & 32 \\
\hline Janjati & 134 & 54 \\
\hline Dalit & 34 & 14 \\
\hline \multicolumn{3}{|l|}{ Economic status of the family } \\
\hline Sufficient for less than 6 months & 48 & 20 \\
\hline Sufficient for 6-12 months & 99 & 40 \\
\hline More than 1 year & 99 & 40 \\
\hline \multicolumn{3}{|l|}{ Age of women } \\
\hline $15-19$ & 9 & 4 \\
\hline $20-24$ & 28 & 11 \\
\hline $25-29$ & 48 & 20 \\
\hline $30-34$ & 46 & 19 \\
\hline $35-39$ & 51 & 21 \\
\hline $40-44$ & 44 & 18 \\
\hline $45-49$ & 20 & 8 \\
\hline \multicolumn{3}{|l|}{ Education of women } \\
\hline Illiterate & 55 & 22 \\
\hline Informal education & 66 & 27 \\
\hline Primary & 31 & 13 \\
\hline Secondary & 75 & 30 \\
\hline SLC and above & 19 & 8 \\
\hline \multicolumn{3}{|l|}{ Occupation of women } \\
\hline Agriculture & 56 & 23 \\
\hline Business & 6 & 2 \\
\hline Service & 6 & 2 \\
\hline Labour & 2 & 1 \\
\hline Housewife & 176 & 72 \\
\hline \multicolumn{3}{|l|}{ Education of husband } \\
\hline Illiterate & 33 & 14 \\
\hline Informal education & 29 & 12 \\
\hline Primary & 47 & 20 \\
\hline Secondary & 100 & 42 \\
\hline SLC and above & 27 & 11 \\
\hline \multicolumn{3}{|l|}{ Occupation of husband } \\
\hline Agriculture & 142 & 58 \\
\hline Business & 15 & 6 \\
\hline Service & 23 & 9 \\
\hline Labour & 32 & 13 \\
\hline Foreign employment & 34 & 14 \\
\hline
\end{tabular}

Distribution of use of family planning and other contributing factors

Table 2: Percentage distribution of use of family planning methods

\begin{tabular}{|c|c|c|}
\hline Characteristics & Frequency & Percent \\
\hline \multicolumn{3}{|l|}{ Use of family planning } \\
\hline Yes & 160 & 65 \\
\hline No & 86 & 35 \\
\hline Total & 246 & 100 \\
\hline \multicolumn{3}{|l|}{ Sources of information of FP } \\
\hline Radio & 134 & 55 \\
\hline TV & 23 & 9 \\
\hline Newspaper & 18 & 7 \\
\hline Friend/Neighbour & 48 & 20 \\
\hline Health worker & 97 & 39 \\
\hline FCHV & 83 & 34 \\
\hline \multicolumn{3}{|l|}{ Discussion with husband about FP } \\
\hline Yes & 226 & 92 \\
\hline No & 20 & 8 \\
\hline Total & 246 & 100 \\
\hline \multicolumn{3}{|l|}{ Types of FP method used } \\
\hline Pill & 26 & 16 \\
\hline Implant & 3 & 2 \\
\hline Dipo & 20 & 13 \\
\hline Condom & 13 & 8 \\
\hline Male sterilization & 65 & 41 \\
\hline Female sterilization & 33 & 21 \\
\hline Total & 160 & 100 \\
\hline \multicolumn{3}{|l|}{ Source of FP methods } \\
\hline Government hospital/mobile camp & 144 & 90 \\
\hline Private/Medical & 13 & 8 \\
\hline Others & 3 & 2 \\
\hline Total & 160 & 100 \\
\hline \multicolumn{3}{|l|}{ Reasons for not using FP method } \\
\hline Didn’t know & 4 & 5 \\
\hline Fear of side-effect & 15 & 17 \\
\hline No need & 67 & 78 \\
\hline Total & 86 & 100 \\
\hline
\end{tabular}

More than three fifth (65\%) of respondents were using any kind of family planning devices or had had permanent family planning. Regarding the sources of information of family planning methods, $55 \%$ had received it from radio, $39 \%$ from health worker, $34 \%$ from female community health volunteer (FCHV) and only 7\% from newspapers. Out of total respondents, $92 \%$ had discussions between spouses. With respect to types of family planning methods, male sterilization was done among $41 \%$ couples, followed by female sterilization (21\%), and a fewer percentage of respondents were using other methods.

With regard to source of family planning methods, $90 \%$ 
received the service from government health institutions or mobile camp. More than three quarters- $78 \%$ - of respondents said no need of family planning as the reason for not using any methods. Those who said they did not need family planning included young women who wanted more children, women whose chances of reproduction has stopped but are still below 49 years of age, or whose husband lives abroad or other places of Nepal.

Table 3: Cross-tabulation of some variables and use of family planning methods

\begin{tabular}{|c|c|c|c|}
\hline \multirow{3}{*}{ Characteristics of women } & \multicolumn{3}{|c|}{$\begin{array}{l}\text { Use of family planning methods } \\
\qquad(\mathrm{N}=246)\end{array}$} \\
\hline & Yes & No & Total \\
\hline & $\begin{array}{l}\text { Frequency } \\
(\%)\end{array}$ & $\begin{array}{l}\text { Frequency } \\
(\%)\end{array}$ & $\begin{array}{l}\text { Frequency } \\
(\%)\end{array}$ \\
\hline \multicolumn{4}{|c|}{ Age group of women in years } \\
\hline $15-19$ & $5(56 \%)$ & $4(44 \%)$ & $9(100 \%)$ \\
\hline $20-24$ & $11(39 \%)$ & $17(61 \%)$ & $28(100 \%)$ \\
\hline $25-29$ & $30(63 \%)$ & $18(38 \%)$ & $48(100 \%)$ \\
\hline $30-34$ & $33(72 \%)$ & $13(28 \%)$ & $46(100 \%)$ \\
\hline $35-39$ & $36(71 \%)$ & $15(29 \%)$ & $51(100 \%)$ \\
\hline $40-44$ & $31(70 \%)$ & $13(30 \%)$ & $44(100 \%)$ \\
\hline $45-49$ & $14(70 \%)$ & $6(30 \%)$ & $20(100 \%)$ \\
\hline \multicolumn{4}{|l|}{ Caste of women } \\
\hline Brahman/Chhetri & $56(72 \%)$ & $22(28 \%)$ & $\begin{array}{c}78 \\
(100 \%)\end{array}$ \\
\hline Janjati & $78(58 \%)$ & $56(42 \%)$ & $\begin{array}{c}134 \\
(100 \%)\end{array}$ \\
\hline Dalit & $26(76 \%)$ & $8(24 \%)$ & $\begin{array}{c}34 \\
(100 \%)\end{array}$ \\
\hline \multicolumn{4}{|l|}{ Economic status of family } \\
\hline $\begin{array}{l}\text { Sufficient for less than } 6 \\
\text { months }\end{array}$ & $35(73 \%)$ & $13(27 \%)$ & $48(100 \%)$ \\
\hline Sufficient for 6-12 months & $60(61 \%)$ & $39(39 \%)$ & $99(100 \%)$ \\
\hline More than 1 year & $65(66 \%)$ & $34(34 \%)$ & $99(100 \%)$ \\
\hline \multicolumn{4}{|l|}{ Education of woman } \\
\hline Illiterate & $38(69 \%)$ & $17(31 \%)$ & $55(100 \%)$ \\
\hline Informal education & $44(67 \%)$ & $22(33 \%)$ & $66(100 \%)$ \\
\hline Primary & $23(74 \%)$ & $8(26 \%)$ & $31(100 \%)$ \\
\hline Secondary & $48(64 \%)$ & $27(36 \%)$ & $75(100 \%)$ \\
\hline SLC and above & $7(37 \%)$ & $12(63 \%)$ & $19(100 \%)$ \\
\hline
\end{tabular}

Fewer women (39\%) of the age group 20-24 used family planning methods than any other age groups. $56 \%$ of women in age group 15-19 and 63\% of 25-29 years used family planning, whereas a higher proportion, about $71 \%$ on average, used family planning in the age groups between 30 to 49 years.

Most of Dalits (76\%) used family planning methods compared to Brahman/Chhetri (72\%) and Janjatis (58\%). A higher percentage of women with the major source of family income 'sufficient for only less than six months' used family planning than couples falling in other two groups. About three quarters $(74 \%)$ of women with primary education had used family planning and it was half of this proportion, i.e., $37 \%$, among women having education SLC and above, and $64 \%, 67 \%$, and $69 \%$ among with secondary education, informal education and illiterates respectively.

\section{DISCUSSION}

The study showed the contraceptive prevalence rate of the VDC as $65 \%$ which is higher than that of nation $50 \% .{ }^{4}$ One of the reasons could be higher educational status of women in the VDC. Unlike the results of NDHS 2011 in which the use of family planning is lower among younger women and older women than among those at intermediate ages, ${ }^{4}$ this study found the percentage of couples using family planning methods less $(39 \%)$ in the age group 20-24, compared to other age groups. The use increased after the age of thirty years $(70 \%$ on average). It could have been because most of them had usually completed their desire for children by the age of 30 which is evident from the high percentage of male and female sterilization as a method of family planning found in the study.

About three quarters (74\%) of women with primary education and $69 \%$ of illiterates used family planning, while there were less proportion of women using family planning with the increase of educational status, with the least percentage (37\%) among those having education SLC and above. Almost similar results were found in NDHS 2011- use of a modern method highest among women with no education and decreases with increasing education.

With respect to types of family planning methods used, the demographic and health survey found female sterilization as the most widely used method (15\%) and half of this (8\%) male sterilization. Contrary to this, the study identified male sterilization as the most commonly used method (41\%) and $21 \%$ female sterilization. It might be because vasectomy camps had been carried out several times in the VDC.

Regarding the source of family planning methods, majority received family planning methods from government health institutions or mobile camp, quite similar to the status of the nation- $69 \%$ of current users getting the methods from government health institutions and the findings are also similar to the results of a study carried out in Ethiopia which found most women obtaining FP methods from the public health sector. ${ }^{4,6}$

Regarding the sources of information of family planning methods, a large proportion of women (64\%) had received it from radio or television, followed by health worker (39\%) and FCHV (34 \%) and others. Similarly, a study in Nigeria found mass media to be the most common source of family planning information, closely followed by health workers. ${ }^{7}$ 


\section{CONCLUSION}

The study showed the percentage of family planning users higher than that of nation, which increased after the age of thirty years but declined with the increase of educational status after primary education. Majority of study population received the information about family planning from mass media followed by health workers or female community health volunteers. The study included fewer variables and small sample size, however, it gives some information about the distribution of family planning methods use in a terai rural area of Chitwan district. The findings indicate that family planning awareness program need to be targeted to couples with secondary and above education, and to younger than thirty years.

\section{REFERENCES}

1. WHO. MDG 5: improve maternal health. Available from http://www.who.int/topics/millennium_development_goals/ maternal_health/en/index.html. [Accessed on Nov 2, 2012].

2. National Planning Commission Nepal. Three Year Interim Development Plan 2010/11-2012/13. Kathmandu, Nepal: National Planning Commission. 2010.

3. Government of Nepal, Ministry of health and population, Department of health services. Annual Report 2009/2010. 2011.

4. MoHP, NEW ERA, Macro Int'1. Nepal Demographic and Health Survey 2011. Ministry of Health and Population, New ERA, and Macro International Inc., Kathmandu, Nepal. 2012.

5. DPHO. Data on family planning. Unpublished data. Available from District Public Health Office, Chitwan, Nepal. $2067 / 068$.

6. Ko IS, You MA, Kim ES, Lee TW, Kim S, Kim YM, et. al. Family planning practice and related factors of married women in Ethiopia. Int Nurs Rev. 2010 Sep; 57(3):377-82.

7. Ikechebelu JI, Joe-Ikechebelu NN, Obiajulu FN. Knowledge, attitude and practice of family planning among Igbo women of south-eastern Nigeria. J Obstet Gynaecol. 2005 Nov; 25(8):792-5. 